\section{Kim są polscy humaniści cyfrowi?}

Maciej Maryl

TEKSTY DRUGIE 2017, NR 1, S. 286-300

DOI: $10.18318 /$ td.2017.1.24

\section{Wtem}

Choć ostatnimi czasy dość głośno o humanistyce cyfrowej, to sam termin pojawił się w Polsce dość późno. Jeśli uznać statystyki Google Trends za miarodajne źródło, to przed jesienią 2012 roku hasło to praktycznie nie pojawiało się w zapytaniach internetowych (zob. rys. 1).

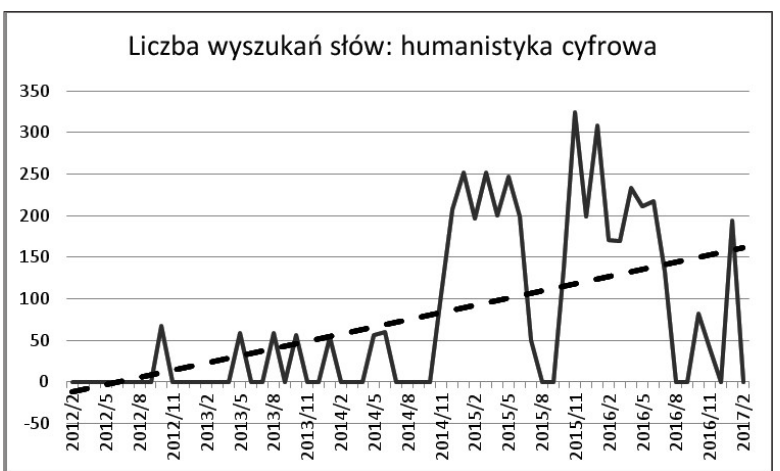

Rys. 1. Wykres wyszukiwań słów: humanistyka cyfrowa w Google (statystyki dla całego świata), przedział miesięczny. Źródło: Google Trends. ${ }^{1}$

1 Warto podkreślić, że nie dysponujemy danymi surowymi - a na wykresie umieszczono jedynie proporcje relatywne względem tygodnia, w którym tych wyszukiwań było najwięcej (18.01.2015). Uwaga
Artykuł napisany w ramach prac Digital Methods and Practices Observatory (DiMPO), Grupy Roboczej DARIAH-ERIC. Dziękuję Nephelie Chatzidiakou (Digital Curation Unit, IMIS-Athena Research Centre) za wstępne przetworzenie wyników.

Maciej Maryl - dr, adiunkt w IBL PAN, kierownik Centrum Humanistyki Cyfrowej IBL PAN, członek Rady Konsorcjum DARIAH-PL. W 2013 r. obronił rozprawę doktorską poświęconą życiu literackiemu w Internecie. Interesuje się komunikacją literacką, nowymi mediami, piśmiennictwem multimedialnym oraz związkami technologii z kulturą. WWW: maryl.org. Kontakt: maciej. maryl@ibl.waw.pl 
Niemal w tym samym czasie (19 grudnia 2012) pojawiło się hasło „Humanistyka cyfrowa" w Wikipedii, definiujące ją bardzo wąsko (lub po prostu błędnie) jako „dział badań humanistycznych zajmujący się człowiekiem i jego wytworami w przestrzeni wirtualnej"2. Wydarzenia te należy wiązać z konferencją "Zwrot cyfrowy w humanistyce” (UMCS, 24-26 października 2012), która oczywiście nie zapoczątkowała cyfrowych badań humanistycznych w kraju ${ }^{3}$, ale nadała nazwę - spolszczając „digital humanities” - różnorodnym przedsięwzięciom badawczym, w których istotną, jeśli nie kluczową rolę odgrywał komponent cyfrowy. Kolejne wydarzenia ugruntowują nowe podejście badawcze i gromadzą praktyków z całego kraju: spotkanie „Historycy cyfrowi” zorganizowane przez ICM UW (8 maja 2013)4, panel „Kulturoznawstwo cyfrowe” pod kierunkiem prof. Radomskiego (UMCS) podczas II Zjazdu Polskiego Towarzystwa Kulturoznawczego (19-21 września 2013)5 , panel „Digital Humanities in Poland: Challenges and Perspectives” podczas konferencji „Teksty Kultury Uczestnictwa” (7-8 października 2013) w IBL PAN ${ }^{6}$.

Równocześnie rozpoczyna się instytucjonalizacja humanistyki cyfrowej - powstają humanistyczne centra cyfrowe, których celem jest koordynacja prac w jednostkach i prowadzenie interdyscyplinarnych badań humanistycznych: Centrum Humanistyki Cyfrowej IBL PAN (2013), Digital Economy Lab UW (2014), Laboratorium Cyfrowe Humanistyki UW (2015). W tym samym czasie obserwujemy nasilenie współpracy instytucjonalnej między polskimi jednostkami i dużymi konsorcjami europejskimi: powstaje koordynowane przez Politechnikę Wrocławską konsorcjum

metodologiczna Google Trends: „Liczby przedstawiają, jak często hasło było wyszukiwane w odniesieniu do najwyższego punktu wykresu w danym czasie i regionie. Wartość 100 oznacza najwyższą popularność hasła. Wartość 50 oznacza, że popularność hasła była dwukrotnie mniejsza. Natomiast $\emptyset$ świadczy o tym, że popularność hasła wynosiła mniej niż $1 \%$ najwyższej wartości". Przerywana linia oznacza trend.

2 Zob.https://pl.wikipedia.org/wiki/Humanistyka_cyfrowa.

3 Por. wyniki ankiety rozpisanej w 2014 roku wśród polskich badaczy, stosujących metody cyfrowe w humanistyce, ukazującej rozmiar zjawiska; M. Werla, M. Maryl, oprac. (2014) Humanistyczne projekty cyfrowe w Polsce (raport z ankiety), Poznań-Warszawa, http://lib.psnc.pl/publication/831.

4 Zob.https://wiki.ceon.pl/research/Public:Historycy_cyfrowi_2013.

5 Zob.http://ptk.edu.pl/zjazdy-ptk/ii-zjazd-ptk-2013/.

6 Zapis panelu: https://www.youtube.com/watch?v=Xcv1Qul5XHQ. 
CLARIN-PL (Common Language Resources and Technology Infrastructure), a Polska zostaje członkiem-założycielem CLARIN-ERIC (2013), IBL PAN rok później zyskuje status członka-obserwatora w NeDiMAH (Network for Digital Methods in the Arts and Humanities), zawiązuje się konsorcjum DARIAH-PL (Digital Research Infrastructure for the Arts and Humanities) i po burzliwym okresie formacyjnym (to temat na odrębną opowieść) zostaje pod przewodnictwem Uniwersytetu Warszawskiego przyjęte do DARIAH ERIC (2015). W ostatnich latach Polska gościła także wielkie konferencje międzynarodowe poświęcone humanistyce cyfrowej: doroczną konferencję CLARIN-ERIC we Wrocławiu (2015) ${ }^{7}$ czy ogromną konferencję Alliance of Digital Humanities Organizations (ADHO) w Krakowie (2016) ${ }^{8}$. Pod koniec 2016 roku LaCH UW organizowało także międzynarodową konferencję „Digital Humanities Centres: Experiences and Perspectives" .

Można więc powiedzieć, że w ostatnich latach humanistyka cyfrowa przeżywa w Polsce gwałtowny rozwój.

\section{Co to jest humanistyka cyfrowa}

Polską definicję z Wikpedii przed chwilą odrzuciłem, jako bardzo wąską i jednostronną, ponieważ zakładała, że cyfrowość odnosi się wyłącznie do przedmiotu dociekań humanistycznych, tj. kultury cyfrowej. Nie chcąc wchodzić w nazbyt szczegółowe roztrząsania, które zepchnęłyby ten tekst na zupełnie inne tory ${ }^{10}$, przytaczam niżej trzy definicje, które dobrze oddają hybrydyczny charakter tego pola i pozwolą zoperacjonalizować ów termin dla dalszych rozważań.

Raz: „Humanistyka cyfrowa [to termin] oznaczający nowe podejścia naukowe i jednostki instytucjonalne, służące zespołowym, transdyscyplinarnym i zaawansowanym cyfrowo badaniom, szkolnictwu i publikacjom. Humanistyka cyfrowa to [...] szeroki wachlarz konwergentnych

7 Zob.https://www.clarin.eu/event/2015/clarin-annual-conference-2015-wroclaw-poland.

8 Zob. http://dh2016.adho.org/.

9 Zob.http://dhlabs2016.lach.edu.pl/.

10 Zainteresowanych czytelników odsyłam do: M. Maryl F5: odświeżanie filologii, "Teksty Drugie” $2014 \mathrm{nr} 2$ (146), s. 9-20 (tam też przypisy do literatury przedmiotu). 
praktyk, służących eksploracji uniwersum, w którym druk nie jest już głównym medium"."1

Dwa: „Projekty z zakresu humanistyki cyfrowej są z definicji oparte na współpracy: łączą techników, bibliotekarzy, przedstawicieli nauk społecznych, artystów, architektów, badaczy komunikacji i informatyków we wspólnym ujmowaniu i rozwiązywaniu problemów, które często cechuje duży wpływ [high impact], zaangażowanie społeczne, szeroki zakres i długotrwałość. Jednocześnie humanistyka cyfrowa to kontynuacja i rozszerzenie tradycyjnego obszaru humanistyki, nie substytucja czy negacja badań humanistycznych"."2

Trzy: „humanistyka cyfrowa stanowi pole w luźnym sensie. Nie suponuję tutaj dobrze zdefiniowanego i ograniczonego pola akademickiego poza tradycyjnymi dyscyplinami humanistycznymi, tylko raczej inkluzywne pojęcie, które pozwoli nam mówić o różnych rodzajach inicjatyw i czynności na przecięciu humanistyki i informatyki lub cyfrowości".13

Kluczowe jest tu uznanie humanistyki cyfrowej nie tyle za konkretną dyscyplinę czy metodę, ile zespół różnych praktyk badawczych, wykorzystujących cyfrową (pierwotnie bądź wtórnie) formę przedmiotu badań. A zatem chodzi tu nie tylko o badanie kultury cyfrowej, ale także o stosowanie metod cyfrowych do badania lub udostępniania dzieł kultury analogowej. Niejednorodność humanistyki cyfrowej znajduje odzwierciedlenie w różnych konceptualizacjach samego kierunku, z których przebija pewna narracja rozwoju. Bardzo dobrze oddają to uwagi Todda Presnera:

Podczas gdy pierwsza fala humanistyki cyfrowej pod koniec lat 9o. XX wieku i w pierwszych latach kolejnej dekady, skupiała się na monumentalnych projektach digitalizacyjnych oraz ustanowieniu infrastruktury technologicznej, obecna, druga fala humanistyki cyfrowej - którą można

11 A. Burdick, J. Drucker, P. Lunenfeld, T. Presner, J. Schnapp Digital_Humanities, The MIT Press, Cambridge, MA 2012, s. 127.

T. Presner Digital Humanities 2.0: A Report on Knowledge, OpenStax CNX. 8 czerwca 2010, http:// cnx.org/contents/2742bb37-7c47-4bee-bb34-of35bda76of3@6,s.3.

13 P. Svensson The Landscape of Digital Humanities, "Digital Humanities Quarterly" 20104.1 http:// digitalhumanities.org:8081/dhq/vol/4/1/000080/000080.html , akapit 12. 
nazwać Humanistyką Cyfrową 2.0 - jest głęboko generatywna, budując środowiska i narzędzia do wytwarzania, przekazywania i udostępniania wiedzy, która jest „zrodzona cyfrowo” i żyje w różnych kontekstach cyfrowych. ${ }^{14}$

Pierwsza fala, według Presnera, koncentrowała się na analizie i przetwarzaniu tekstu w ramach poszczególnych dyscyplin, druga zaś przynosi nowe paradygmaty czy metodologie. Owa „druga fala" ma chyba docelowo stać się modelem dla wszystkich badań humanistycznych, nie tylko tych cyfrowych bo w końcu wszystko powoli staje się cyfrowe. W tym kierunku właśnie zdają się zmierzać uwagi dwóch kolejnych badaczek. Tara McPherson wyróżnia trzy typy humanistów cyfrowych: humaniści komputerowi (computing humanists), kładący nacisk na projekty infrastrukturalne (archiwizację, digitalizację, zachowanie dziedzictwa), humaniści blogujący (blogging humanists), zainteresowani nowoczesnymi możliwościami publikacji i komunikacji naukowej, oraz najnowszy typ humanistów multimodalnych (multimodal humanists), którzy łączą zainteresowanie bazami danych, narzędziami badawczymi czy nowymi formami współpracy, wykorzystując jednocześnie potencjał mediów wizualnych i audialnych ${ }^{15}$. Chodzi tu zatem o pewne stopnie czy etapy, które od remediacji warsztatu naukowego (dostosowanie prac czy publikacji do nowych metod) prowadzą do nowej formuły uprawiania nauki. Podobne podejście znajdujemy także u innych badaczy. Cathy Davidson stosuje rozróżnienie na Web 1.0 i 2.0, by naszkicować historię humanistyki obliczeniowej (humanities computing) pierwszej generacji, którą określa mianem Humanistyki 1.o, oraz „omówić możliwości lub zagrożenia usieciowionej, interaktywnej, zespołowej Humanistyki 2.0"16. Ów drugi etap - humanistyka multimodalna czy Humanistyka 2.0 - to punkt dojścia dla całej humanistyki - jest to nowa, usieciowiona humanistyka, korzystająca z nowoczesnych narzędzi.

Jest też coś, co David Berry nazwał "trzecią falą" humanistyki cyfrowej, czyli krytyczny namysł nad epistemologią narzędzi cyfrowych czy wizji świata, którą owe technologie pośrednio promują. Berry postuluje „przyjrzeć się

T. Presner Digital Humanities 2.0..., s. 6.

T. McPherson Introduction: Media Studies and the Digital Humanities, "Cinema Journal” Winter 2009 48:2, S. 119-120.

C.N. Davidson Humanities 2.0: Promise, Perils, Predictions, "Publications of the Modern Language Association of America (PMLA)" 2008 123:3, s.709, zob. omówienie tych dwóch koncepcji w: P. Svensson The Landscape...., akapit 15. 
cyfrowemu komponentowi humanistyki cyfrowej w świetle specyfiki jego medium, by analizować, jak przemiany mediów wytwarzają przemiany epistemologiczne"17. Propozycja Berry'ego jest zakorzeniona w software studies i platform studies, ale podobne pytania stawiają inni badacze, jak Richard Rogers (,wykorzystujcie metody medium do badań, które dotyczą czegoś więcej niż kultury cyfrowej”18), Alan Liu (postulat „metodologicznej infrastruktury, w której kulturowo-świadoma technologia uzupełnia się z technologicznie-świadomymi badaniami kultury”) ${ }^{19}$ czy Franco Moretti („Byłoby wspaniale, gdyby pewnego dnia wielkie zbiory danych przywiodły nas z powrotem do wielkich pytań") ${ }^{20}$. W najbardziej radykalnym wydaniu owa krytyka przybiera formę ataku na humanistykę cyfrową jako przejaw neoliberalnej kolonizacji uniwersytetu i zawłaszczenie ostatniego bastionu oporu, jakim jest humanistyka ${ }^{21}$.

A zatem, w pewnym uproszczeniu, zaproponowałbym następujące rozumienie tych etapów: pierwsza fala humanistyki cyfrowej dotyczy digitalizacji i remediacji tradycyjnego warsztatu badawczego dyscyplin (zaliczymy do niej skanowanie tekstów i obiektów, budowę cyfrowych archiwów i katalogów, tworzenie korpusów, adnotowanie tekstów itd.); fali drugiej towarzyszy rozpoznanie i wykorzystywanie możliwości dalszego przetwarzania materiału cyfrowego pozyskanego w fazie pierwszej, czyli wykorzystanie nowego medium do tworzenia nowych metod badawczych i gatunków komunikacji naukowej (narzędzia do badania i wizualizacji, badania na dużych zbiorach materiałów), oraz fala trzecia, czyli krytyczna analiza ograniczeń epistemologicznych medium i samych założeń humanistyki cyfrowej.

Na gruncie polskim też można próbować zastosować taką periodyzację. Do fazy pierwszej zaliczylibyśmy np. rozwój bibliotek cyfrowych w Polsce zapoczątkowany wdrożeniem formatu dLibra (1999), pojawienie się pierwszych, prostych edycji internetowych w Wirtualnej Bibliotece Literatury

D.M. Berry The Computational Turn: Thinking About the Digital Humanities, "Culture Machine", 2011 Vol. 12, https://www.culturemachine.net/index.php/cm/article/view/440/470, s. 12.

R. Rogers Digital methods, The MIT Press, Cambridge, MA 2013, s. 5.

A. Liu Where Is Cultural Criticism in the Digital Humanities, w: Debates in the Digital Humanities, ed. by M.K. Gold, University of Minnesota Press, Minneapolis 2012, s. 502. Por. F. Moretti Pomiar literatury, w niniejszym numerze "Tekstów Drugich".

Tu szczególnie interesujący wydaje się niedawny tekst D. Allington, S. Brouillette, D. Golumbia Neoliberal Tools (and Archives): A Political History of Digital Humanities, "Los Angeles Review of Books", May 1 2016, https://lareviewofbooks.org/article/neoliberal-tools-archives-politicalhistory-digital-humanities/\#!, a także dyskusja, jaką wywołał. 
Polskiej (2001) czy budowę Słowosieci - polskiej wersji WordNetu (2005). Do fazy drugiej np. budowę narzędzi lingwistycznych do analizy tekstu, rozwój badań stylometrycznych, eksperymentalne programy edytorskie (np. Magik z 2007) ${ }^{22}$ czy nową odsłonę Polony (2013). Dzisiejsze dyskusje o cyfryzacji, polityce open access, humanistyce i roli narzędzi cyfrowych mogą zwiastować powoli nadchodzącą fazę trzecią.

W niniejszym artykule chcę wykorzystać tę gradację do pisania o kompetencjach humanistów cyfrowych, odrzucając przy tym aspekt diachroniczny, traktując opisywane tu fale jako odmienne obszary wykorzystania technologii cyfrowych w humanistyce, wymagające różnych kompetencji. Innymi słowy, zamierzam przyjrzeć się humanistyce cyfrowej jako pewnemu spektrum praktyk i kompetencji o różnym stopniu złożoności.

$\mathrm{Z}$ tejże przyczyny w niniejszym tekście proponowałbym stopniowalne definiowanie „humanistów cyfrowych" przez umieszczanie ich na spektrum, od tych korzystających z podstawowych narzędzi po bardziej zaawansowanych użytkowników. Pozycja na spektrum zależy od stopnia „cyfryzacji” warsztatu i świadomego korzystania z technologii do osiągnięcia celów badawczych. W takiej perspektywie mianem cyfrowych należy określić wszystkich humanistów - lub prawie wszystkich, jeśli wykluczymy tych, którzy z komputerami nie mają nic wspólnego - różnica tkwi wyłącznie w stopniu włączenia cyfrowych narzędzi do swojego warsztatu. Wydaje się, że większość czytelników tego tekstu to właśnie humaniści cyfrowi, aplikujący w różnym stopniu dostępne narzędzia i zasoby w swoich własnych badaniach. W tym artykule chciałbym pokazać, że obecnie humanistyka cyfrowa najbardziej kojarzy się z pierwszą falą (i takie są też główne cele wykorzystania metod cyfrowych). Za materiał do dyskusji posłużą wyniki europejskiego sondażu przeprowadzonego przez konsorcjum DARIAH.

\section{Kim są humaniści cyfrowi w Polsce}

Europejski sondaż praktyk oraz potrzeb cyfrowych w humanistyce i naukach o sztuce (European survey on scholarly practices and digital needs in the arts and humanities) został przeprowadzony na przełomie 2014 i 2015 roku przez Obserwatorium Cyfrowych Metod i Praktyk (Digital Methods and Practices Observatory - DiMPO) - grupę roboczą europejskiego konsorcjum 
DARIAH $^{23}$. Ankietę kolportowano w 10 językach i uzyskano odpowiedzi od 2177 respondentów z całej Europy, w tym 154 z Polski (por. rys. 2). Polską wersję opracowało Centrum Humanistyki Cyfrowej IBL PAN we współpracy z Poznańskim Centrum Superkomputerowo-Sieciowym ${ }^{24}$. Przegląd wyników europejskich można znaleźć w opublikowanej niedawno broszurze ${ }^{25}$. W tym miejscu skupię się na próbie polskiej, by - porównując ją częściowo z wynikami ogólnoeuropejskimi - wyciągnąć wnioski na temat specyfiki polskiej humanistyki cyfrowej. Przytaczam tu wyłącznie wyimki z badań - wkrótce ma się ukazać odrębny raport.

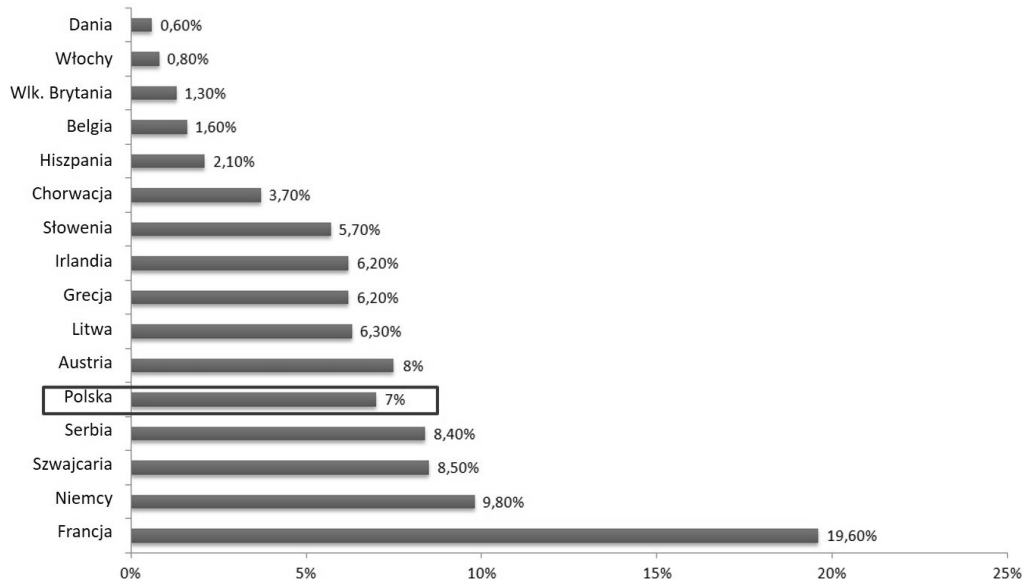

Rys. 2. Próba europejska z podziałem na państwa i procentowym udziałem respondentów. N=2177.

Należy wyraźnie podkreślić na wstępie, że ankieta nie jest reprezentatywna. Respondentów rekrutowano w wyniku akcji promocyjnej i metodą kuli śniegowej, co uniemożliwia rozciąganie wyników na całą populację badaczy z dziedziny humanistyki w Polsce. W ankiecie mógł wziąć udział każdy i wielokrotnie zachęcaliśmy do tego różnymi kanałami. Dlatego też ze szczególną ostrożnością należy traktować wyniki ilościowe, gdyż nie mówią nam nic

23 Zob. http://dimpo.dcu.gr/.

24 Tłumaczenie: M. Maryl, korekta: M. Kozak, P. Wciślik, M. Werla, testy: J. Andrusiewicz, Ł. Bukowiecki, A. Wójtowicz.

25 C. Dallas, N. Chatzidiakou, M. Maryl, A. Bernardou, C. Clivaz, J. Cunningham, M. Dabek i in. Europejski sondaż praktyk cyfrowych whumanistyce inaukach o sztuce. Najważniejsze wyniki (wersja Polska), przeł. M. Maryl, 30 Października 2016, doi:10.5281/zenodo.259522. 
o faktycznym rozkładzie cech w populacji polskich badaczy. Z drugiej jednakże strony badanie można traktować jako swoisty „humanistów cyfrowych obraz własny", czyli zarys postaw i zainteresowań osób, które w jakimś zakresie do humanistyki cyfrowej aspirują, przynajmniej na tyle, że zgodziły się poświęcić 10 minut na wypełnienie ankiety złożonej z 21 pytań. Nie możemy zatem zakładać, że wszyscy badacze korzystający z metod cyfrowych mieli taką samą szansę wziąć udział w badaniu, ale mamy prawo przypuszczać, że udało się dotrzeć do osób i instytucji najbardziej aktywnych na tym polu (członków konsorcjum CLARIN-PL, formującego się wówczas DARIAH-PL czy środowiska bibliotek cyfrowych), co oczywiście nie oznacza, że te środowiska są równo reprezentowane w badaniu. Tak zatem należy rozumieć te wyniki i tak będę je traktował w niniejszym artykule - jako zapis postaw polskich humanistów cyfrowych na wstępnym etapie instytucjonalizacji tego kierunku w Polsce.

Problem reprezentatywności dobrze widać przy porównaniu przekroju dyscyplinarnego polskiej próby z bardziej zróżnicowaną próbą ogólnoeuropejską (rys. 3). Wydaje się, że rozkład ten dobrze oddaje kształt humanistyki cyfrowej w Polsce, gdzie językoznawcy, literaturoznawcy, historycy i - w nieco mniejszym stopniu reprezentowani w próbie - kulturoznawcy są najaktywniejsi, jeśli wziąć pod uwagę, konferencje, warsztaty czy współpracę z europejskimi konsorcjami czy sieciami. Należy przy tym podkreślić, że ów obraz jest wyjątkowo dynamiczny w przypadku Polski, gdzie obserwujemy stały wzrost zainteresowania humanistyką cyfrową.

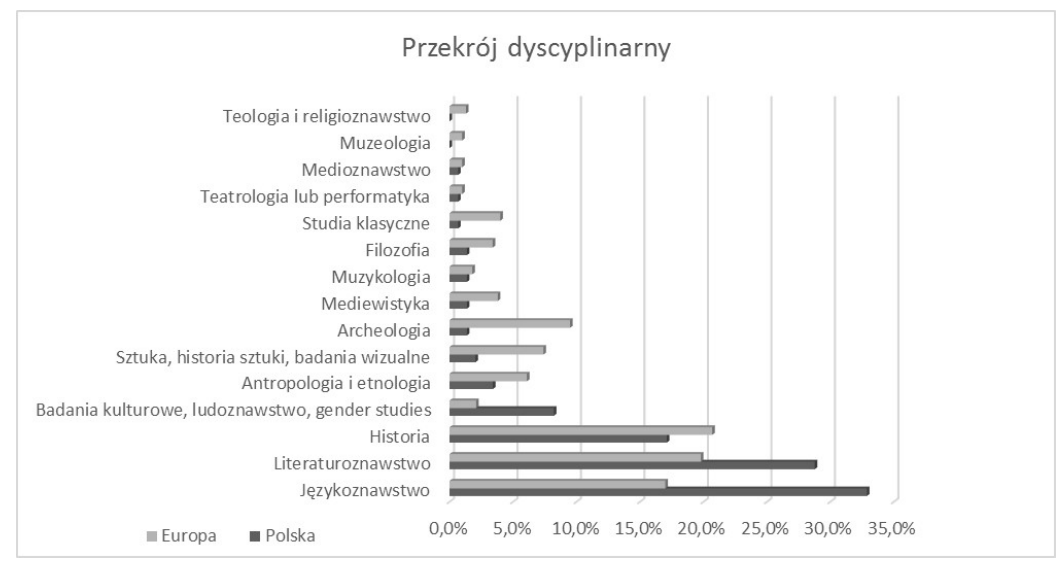

Rys. 3. Przekrój dyscyplinarny polskiej humanistyki cyfrowej w porównaniu z próbą europejską. 
Ciekawie kształtuje się też status zawodowy respondentów (rys. 4).Większość z nich stanowią adiunkci (29,6\%) i profesorowie (22,5\%). Co ciekawe, proporcje próby europejskiej są nieco inne - tu większość stanowią profesorowie $(26,6 \%)$, a adiunkci to $17,2 \%$. Jeżeli dodatkowo weźmiemy pod uwagę doktorantów (26,1\% w próbie polskiej i $24,9 \%$ w europejskiej), to wyraźnie widać, że humanistyką cyfrową w Polsce interesują się młodsi czy też mniej zaawansowani badacze.

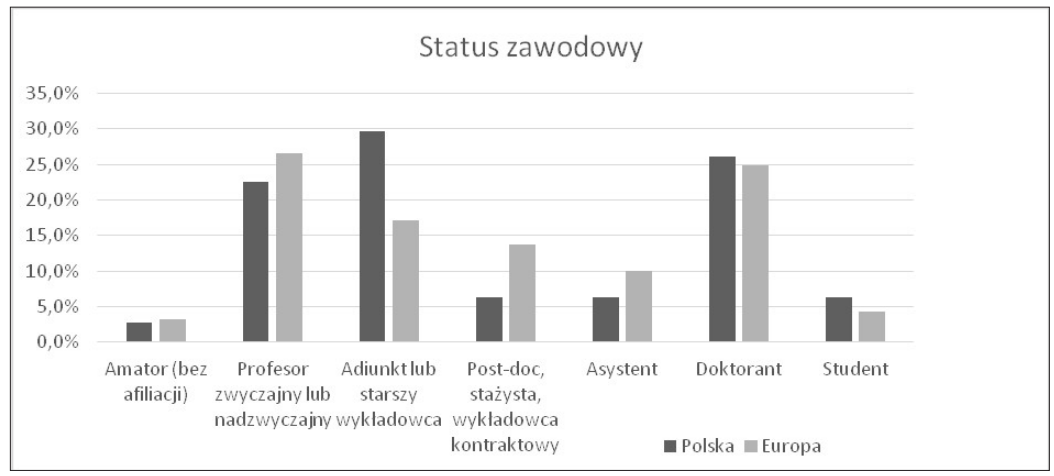

Rys. 4. Status zawodowy respondentów.

Jeżeli przyjrzeć się, jak badani odpowiadali na pytanie dotyczące ich potrzeb w kontekście usług oferowanych przez europejskie infrastruktury badawcze, dobrze widać ową gradację, o której pisałem wcześniej (rys. 5). Badanych poproszono o oznaczenie istotności danych usług dla ich praktyki badawczej na skali od jeden (najmniej ważne) do dziesięciu (najważniejsze). Niemal jednogłośnie zgodzili się, że najważniejsze dla ich badań jest łatwiejsze wyszukiwanie i lepszy dostęp do istniejących materiałów badawczych i danych (średnia 9,42) oraz digitalizacja materiałów badawczych i danych obecnie w formie niecyfrowej (średnia 9,21). Dość wysoko w hierarchii potrzeb plasują się także łatwiejsze wyszukiwanie i lepszy dostęp do cyfrowych narzędzi i oprogramowania (średnia 8,22), kontakt z innymi badaczami, grupami badawczymi i instytucjami istotnymi z punktu widzenia własnych badań (średnia 7,86) oraz techniczne wsparcie w zakresie infrastruktury cyfrowej, narzędzi i oprogramowania (średnia 7,01). Mniejszą istotność przypisano takim zagadnieniom jak internetowe wsparcie czy kursy i warsztaty dotyczące metod cyfrowych. Wydaje się, że wyniki pokazują dość zachowawczą postawę respondentów, których najbardziej interesuje usprawnienie własnych praktyk badawczych (dostęp do materiałów, narzędzi 
i kontakt z innymi badaczami) niż poznawanie nowych metod i narzędzi (porady, wsparcie, kursy).

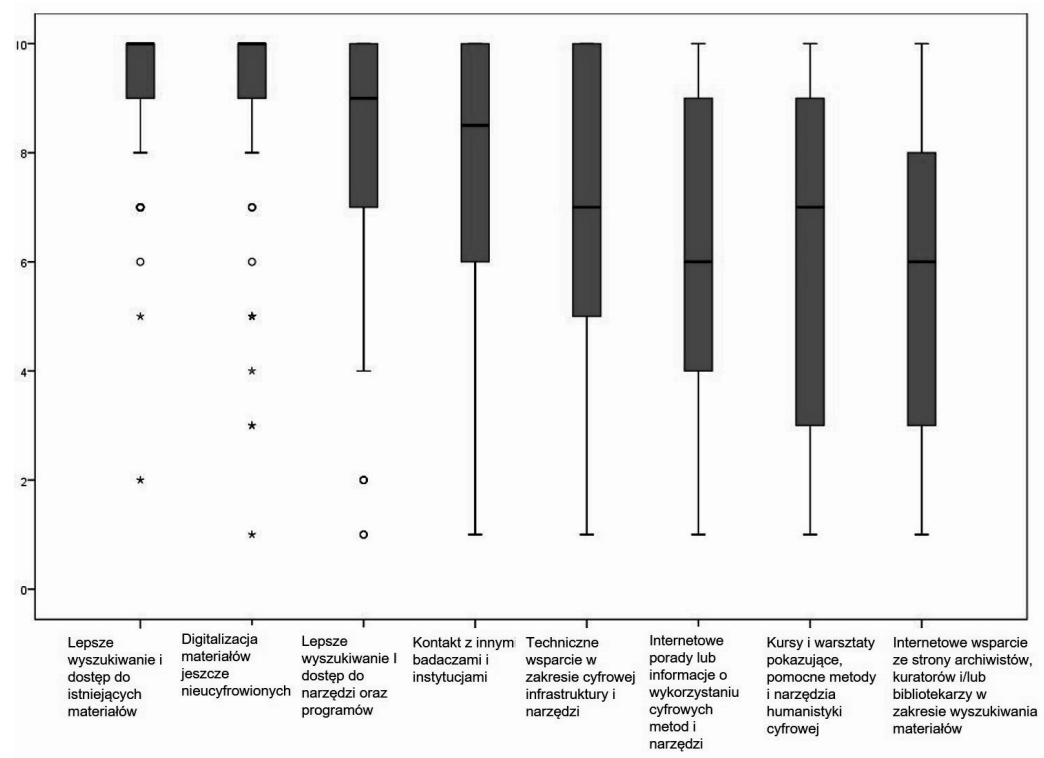

Rys. 5. Istotność usług oferowanych przez infrastruktury badawcze.

Gradację widać także na przykładzie metod i narzędzi - zapytani o narzędzia do przechowywania i przetwarzania danych prawie wszyscy respondenci wskazują na edytor tekstu, ale już tylko połowa korzysta z arkuszy kalkulacyjnych, a jeszcze mniejsza liczba z bardziej zaawansowanych metod.

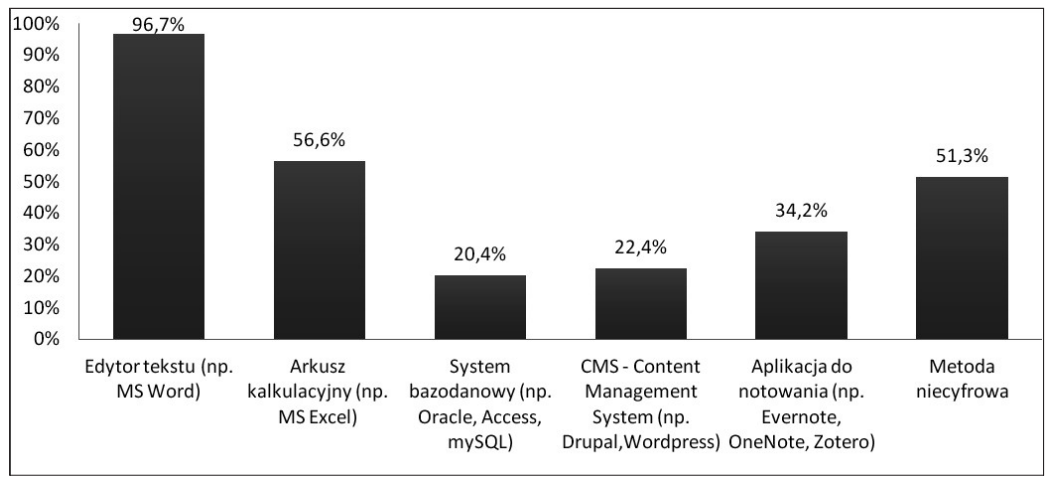

Rys. 6. Aplikacje wykorzystywane do przechowywania i przetwarzania materiałów badawczych. 
W odpowiedzi na pytanie, do jakich celów chcą wykorzystywać metody i narzędzia cyfrowe, większość respondentów wskazała na podstawowe czynności badawcze, jak odkrywanie, zbieranie i tworzenie materiałów badawczych $(90,1 \%)$, publikowanie wyników $(80,3 \%)$ czy organizowanie i przechowanie materiałów (78,3\%). Nieco mniejsza liczba badanych była zainteresowana wykorzystaniem narzędzi do przetwarzania, analizowania i wizualizowania materiałów (71,7\%) czy ich wzbogacania (65,8\%) (rys. 7). Dobrze tu widać - by przywołać omawiane wyżej dystynkcje McPherson że istotniejsze są cechy właściwe humanistom komputerowym i blogującym niż multimodalnym.

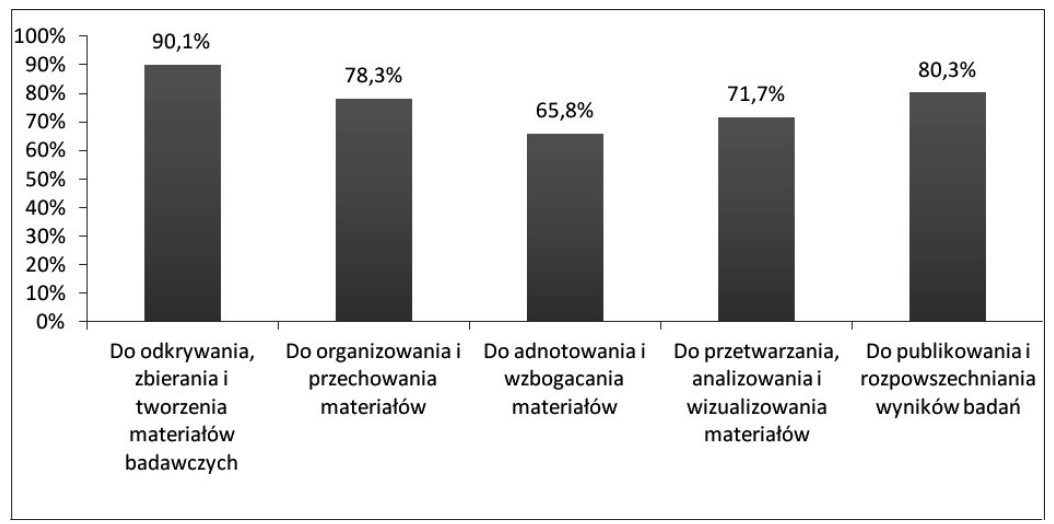

Rys. 7. Cele, do których respondenci wykorzystują metody lub narzędzia cyfrowe.

Respondentów, którzy przyznali, że korzystają lub chcieliby korzystać z cyfrowych metod i narzędzi, poproszono o wskazanie konkretnych przykładów. Pytanie otwarte pozwoliło badanym na udzielenie swobodnych odpowiedzi, które następnie zakodowano, przyporządkowując je do jednej z kategorii czynności badawczych (rys. 7).

Ze względu na jakościową naturę tego pytania i wysoki stopień różnorodności odpowiedzi nie można tu dokonywać żadnych porównań ilościowych na podstawie częstości wskazania danego narzędzia. Należy jednak dodać, że najwięcej przykładów zaklasyfikowano do kategorii pierwszej (odkrywanie, zbieranie i tworzenie materiałów badawczych), co w pewnym sensie pogłębia obserwację omówioną wyżej - pojęcie cyfrowych metod i narzędzi wydaje się wciąż mocniej kojarzone z ułatwianiem dostępu do treści cyfrowych. Wszystkie podane niżej przykłady narzędzi zostały wskazane przez badanych. 
Do ogólnych narzędzi badawczych (przydatnych na wszystkich etapach procesu badawczego) można zaliczyć edytory tekstu i aplikacje do notowania (np. MS Word, Evernote), języki i narzędzia programistyczne (np. html, xml, javascript, IDE), środki do komunikacji z zespołem badawczym (komunikatory, e-mail, aplikacje do zarządzania pracą grupową) czy sprzęt (tablet, smartfon, czytnik e-booków, laptop).

Do odkrywania, zbierania i tworzenia materiałów badawczych respondenci wykorzystują wyszukiwarki (bibliograficzne bazy danych, katalogi bibliotek, wyszukiwarki internetowe). Korzystają przy tym z następujących zasobów: repozytoria i akademickie portale społecznościowe (np. Academia.edu, ResearchGate, CEEOL), zasoby pełnotekstowe (np. Google books), archiwa, kolekcje cyfrowych map, platformy video, zasoby lingwistyczne (słowniki, korpusy), zbiory danych, witryny tematyczne (np. platformy edukacyjne czy specjalistyczne). Do pozyskiwania materiałów wykorzystuje się także sprzęt do zbierania danych ze świata fizycznego (np. GPS, drony, skanery 3D, aparaty cyfrowe), a także narzędzia do zbierania danych z sieci (np. „data scrapers", narzędzia do rejestrowania rozgrywki w grach video).

Do organizowania danych badawczych wykorzystuje się menedżery bibliografii (np. Zotero, Mendeley) czy zakładek (np. Delicious), specjalistyczne narzędzia do zarządzania korpusem tekstowym lub bazą danych. Do przechowywania danych respondenci wykorzystują aplikacje do archiwizacji na dyskach twardych i w chmurze, zaś wzbogacają je za pomocą funkcji dostępnych w aplikacjach do zarządzania danymi (np. dodawanie adnotacji w menedżerze cytowań) czy specjalistycznych narzędzi do adnotowania tekstów (np. oXygen).

Do przetwarzania materiałów wykorzystuje się aplikacje do edytowania audio i video (np. Adobe Premiere), edytory tekstu (np. MS Word), aplikacje graficzne (np. Corel), arkusze kalkulacyjne (np. MS Excel). Badani analizują je za pomocą narzędzi do analizy obrazu, treści (np. MAXQDA), danych, języka (np. Wordsmith, narzędzia CLARIN, AntConc) czy pakietów statystycznych (np. SPSS, R). Do wizualizacji wykorzystują różne narzędzia i aplikacje (np. Gephi, Voyant, Wordle, R).

W procesie publikacji i rozpowszechniania wyników badani wykorzystują edytory tekstu (np. MS Word, Scrivener), specjalistyczne oprogramowanie wydawnicze (np. XeTex, BibLaTex; Open Journal System), platformy blogowe (np. Wordpress) oraz oprogramowanie i sprzęt do prezentacji (np. rzutnik, MS PowerPoint, Prezi). 


\section{Epilog}

W niniejszym artykule próbowałem pokazać, że narzędzia cyfrowe wydają się dość dobrze zakorzenione na wstępnych etapach procesu badawczego i stopniowo - wraz z rozwojem i popularyzacją metod oraz infrastruktur badawczych - zwiększa się ich zastosowanie. To, że „druga fala” humanistyki cyfrowej nie rozwinęła się jeszcze w pełni, może wynikać z kilku czynników, które chciałbym tu na koniec skrótowo omówić.

Po pierwsze, rozproszenie - specyfika polskiej humanistyki cyfrowej polega także na tym, że instytucjonalizuje się ona mniej więcej dekadę po podobnych procesach w USA czy w Europie Zachodniej. Wiele zespołów pracowało często w oderwaniu od siebie i dopiero stopniowe powstawanie wyspecjalizowanych komórek w ramach jednostek czy zrzeszanie się instytucji w konsorcjach pozwoliło ulepszyć wymianę informacji i wiedzy. Nadal jednak pozostaje wiele do zrobienia.

Po drugie, zarządzanie - humanistyka cyfrowa jest dziś w Polsce dyscypliną trojga resortów: nauki, kultury i cyfryzacji. Brak spójnej i skoordynowanej polityki cyfrowej, wspólnych wymagań i standardów, pogłębia tylko chaos i rozproszenie, zamiast im przeciwdziałać

Po trzecie, pieniądze - trudno się spodziewać zaawansowanej technologii w kraju, który wykłada na naukę o,8\% PKB... Projekty cyfrowe są kosztowne i muszą być także podtrzymywane w przyszłości. Zwróćmy uwagę, że nie ma obecnie żadnego konkursu na granty z zakresu humanistyki cyfrowej (wyjąwszy może konkursy w ramach Programu Operacyjnego Polska Cyfrowa, które dotyczą jednak wyłącznie udostępniania zasobów).

Bez rozwiązania tych trzech kwestii trudno spodziewać się gwałtownego rozwoju humanistyki cyfrowej w Polsce. Postęp humanistyki cyfrowej polegałby na wytworzeniu i upowszechnieniu standardowych narzędzi, które byłyby przydatne do przygotowywania materiałów źródłowych oraz do zastosowania na różnych etapach procesu badawczego w humanistyce. 


\section{Abstract}

\section{Maciej Maryl}

THE INSTITUTE OF LITERARY RESEARCH OF THE POLISH ACADEMY OF SCIENCES (WARSAW)

Who Are Polish Digital Humanists?

To sketch a profile of Polish digital humanists, Maryl draws on the results of a European survey on scholarly practices and digital needs in the arts and humanities. This survey was conducted in 2014 and 2015 by the Digital Methods and Practices Observatory (DiMPO), a working group of the European consortium DARIAH. The results are analysed in the context of the concept of waves of digital humanities: the first wave is simple digitization, the second entails the use of advanced digital methods, the third harnesses critical reflection on the epistemology of digital instruments. Maryl proposes to classify digital humanists by placing them on different points on a spectrum, from those using basic tools to the most advanced users.

\section{Keywords}

digital humanities, Digital Methods and Practices Observatory, DARIAH, digitalization, methodology 